\title{
Biologia reprodutiva e polinização de duas espécies de Polystachya Hook. no Sudeste do Brasil: evidência de pseudocleistogamia em Polystachyeae (Orchidaceae) $^{1}$
}

\author{
EMERSON R. PANSARIN ${ }^{2,3}$ e MARIA DO CARMO E. AMARAL ${ }^{2}$
}

(recebido: 18 de agosto de 2005; aceito: 27 de julho de 2006)

\begin{abstract}
Reproductive biology and pollination of two species of Polystachya Hook. in southeastern Brazil: evidence of pseudocleistogamy in Polystachyeae (Orchidaceae)). Phenology, floral biology, pollinators, breeding system and natural fruit set of Polystachya estrellensis Rchb. f. and P. concreta (Jacq.) Garay \& H. R. Sweet were studied in mesophytic forests at Serra do Japi, and in mangroves at a seashore plain at Picinguaba, respectively. Both study areas are natural reserves in southeastern Brazil. Both species flower in summer, are epiphytes and produce terminal inflorescences with up to 150 non-resupinate flowers. The flowers produce a citric fragrance, mainly in the warmest hours of the day. Both species are pollinated by solitary and social small native bees, which collect pseudopollen from the lip of the flowers. The pollinarium is placed frontally on the head of the bees, when they are collecting pseudopollen. Polystachya estrellensis and P. concreta are self-compatible. The majority of flowers of $P$. estrellensis (96,7\%) is cleistogamous, while $P$. concreta produces only chasmogamous flowers. The cleistogamous flowers of $P$. estrellensis present dimensions and number of floral elements identical to the chasmogamous, a phenomenon called pseudocleistogamy. The chasmogamous flowers of $P$. estrellensis, as well as all flowers of $P$. concreta are pollinator dependent. The natural fruit set of $P$. estrellensis was higher than that of $P$. concreta as a consequence of pseudocleistogamy. In mesophytic forests of the Serra do Japi, in which the fruit set of several orchid species is low, mainly because of pollinator scarcity, the strategy presented by P. estrellensis is an important factor that increases the reproductive success of this species, compared with to the non-autogamous members of Epidendroideae that occur in the same region.
\end{abstract}

Key words - cleistogamy, Orchidaceae, Polystachya, pseudopollen, reproductive biology

RESUMO - (Biologia reprodutiva e polinização de duas espécies de Polystachya Hook. no Sudeste do Brasil: evidência de pseudocleistogamia em Polystachyeae (Orchidaceae)). A fenologia, a biologia floral e reprodutiva, e o sucesso reprodutivo de Polystachya estrellensis Rchb. f. e P. concreta (Jacq.) Garay \& H.R. Sweet foram estudados em matas mesofíticas semidecíduas da Serra do Japi (Jundiaí, SP), e na planície litorânea de Picinguaba (Ubatuba, SP), respectivamente. Ambas as espécies florescem no verão. Elas são principalmente epífitas e produzem inflorescências terminais com até 150 flores não ressupinadas. As flores exalam odor cítrico suave, principalmente nas horas mais quentes do dia. Ambas as espécies foram polinizadas por pequenas abelhas nativas, solitárias e sociais, que coletam pseudopólen do labelo das flores. O polinário é depositado na face frontal da cabeça das abelhas, enquanto elas recolhem pseudopólen. Tanto $P$. estrellensis como $P$. concreta são autocompatíveis. A maioria das flores de $P$. estrellensis (96,7\%) é cleistógama, enquanto $P$. concreta produz apenas flores casmógamas. As flores cleistógamas de $P$. estrellensis apresentam tamanho e número dos elementos florais igual ao das flores casmógamas, fenômeno conhecido como pseudocleistogamia. Todas as flores de $P$. concreta, assim como as flores casmógamas de $P$. estrellensis, necessitam de um polinizador para transferência de pólen. A taxa de frutificação de $P$. estrellensis em condições naturais é maior que em $P$. concreta, principalmente por causa do grande número de flores pseudocleistógamas produzidas. Em matas mesofíticas semidecíduas da Serra do Japi, onde a taxa de frutificação de várias espécies de orquídeas é baixa, principalmente devido à escassez de polinizadores, a estratégia apresentada por $P$. estrellensis é um fator que contribui para o sucesso reprodutivo da espécie, comparado com as Epidendroideae não autógamas que ocorrem na região.

Palavras-chave - biologia reprodutiva, cleistogamia, Orchidaceae, Polystachya, pseudopólen

\section{Introdução}

Polystachya Hook. (Epidendroideae: Polystachyeae) é um gênero pantropical com aproximadamente 150

\footnotetext{
1. Parte da dissertação de mestrado do primeiro autor, Programa de Pós-Graduação em Biologia Vegetal da Universidade Estadual de Campinas.

2. Universidade Estadual de Campinas, Instituto de Biologia, Departamento de Botânica, Caixa Postal 6109, 13083-970 Campinas, SP, Brasil.

3._Autor para correspondência: epansarin@uol.com.br
}

espécies (Ackerman 1995, Morrison 1997). A maioria delas ocorre na África, entretanto várias espécies ocorrem em áreas tropicais das Américas (Dressler 1993). Espécies de Polystachya são polinizadas por pequenas abelhas que coletam pseudopólen das flores (Dressler 1993). Pseudopólen são estruturas derivadas da fragmentação de tricomas moniliformes e pluricelulares (van der Pijl \& Dodson 1966, Davies \& Winters 1998, Davies et al. 2000, 2002, Davies \& Turner 2004a, b), que estão presentes em algumas orquídeas, 
como em espécies de Eria (Davies \& Turner 2004b), Dendrobium (Kjellsson \& Rassmussen 1987, Davies \& Turner 2004a), Maxillaria (van der Pijl \& Dodson 1966, Davies \& Winters 1998, Davies et al. 2000, Singer \& Koehler 2004), Polystachya (Davies et al. 2002), bem como em outras famílias de angiospermas (Simpson \& Neff 1981). O pseudopólen de várias espécies de Maxillaria, Polystachya e Eria contém proteína e amido (Davies et al. 2000, 2002, Davies \& Turner 2004b). No pseudopólen de algumas espécies de Maxillaria também foi detectada a presença de lipídios (Davies et al. 2000). Polystachya flavescens (Lindl.) J.J. Sm., que produz pseudopólen como recurso, é polinizada por fêmeas de Dialictus aff. creberrimus (Halictidae), na Flórida (Goss 1977). Pettersson \& Nilsson (1993), no entanto, revelaram que Polystachya rosea Ridl., que ocorre em Madagascar, é polinizada por engano, devido ao polimorfismo das flores. Polystachya rosea é polinizada por duas espécies de Halictidae do gênero Lasioglossum (Pettersson \& Nilsson 1993). De acordo com Davies et al. (2002), o oferecimento de pseudopólen como recurso no gênero Polystachya ocorre principalmente em espécies que pertencem à seção Polystachya. Entre as espécies pertencentes a essa seção estão $P$. concreta (Jacq.) Garay \& H. R. Sweet e P. estrellensis Rchb. f. Polystachya concreta distribui-se nos neotrópicos, embora alguns autores revelem que essa espécie apresente distribuição pantropical (Ackerman 1995). Polystachya estrellensis também é uma espécie de ampla distribuição, sendo encontrada em ambientes bastante diversos no Brasil (Pabst 1950).

Em Orchidaceae a maioria das espécies é autocompatível. No entanto, a ocorrência de autopolinização tende a ser evitada principalmente devido à existência de barreiras mecânicas da própria flor (van der Pijl \& Dodson 1966, Dressler 1981, Catling \& Catling 1991). Autopolinização espontânea tem sido identificada em várias espécies de orquídeas (van der Pijl \& Dodson 1966, Catling 1990, Catling \& Catling 1991). A autopolinização é considerada como um processo complexo que pode acontecer de diversas maneiras (Lloyd \& Schoen 1992). Uma delas é a cleistogamia, um tipo de autogamia que tem sido identificado em mais de 56 famílias, incluindo Orchidaceae (Lord 1981, van der Pijl \& Dodson 1966). A maioria das espécies de orquídeas que apresenta flores cleistógamas exibe cleistogamia do tipo completa, na qual todas as flores de cada indivíduo são cleistógamas, havendo modificação na forma das flores, como redução no tamanho de estames e no número e dimensão dos elementos da corola (Lord 1981). Alguns gêneros de Orchidaceae, no entanto, podem apresentar tanto flores casmógamas quanto cleistógamas na mesma planta (van der Pijl \& Dodson 1966), um sistema denominado pseudocleistogamia (Lord 1981).

Apesar do crescente número de estudos sobre polinização e biologia reprodutiva em Orchidaceae, eles ainda são muito escassos quando comparados ao grande número de espécies presentes na família. De acordo com Davies et al. (2002) pouco é conhecido sobre polinização e biologia reprodutiva de espécies que oferecem pseudopólen como recurso, sendo esse o primeiro estudo de biologia floral realizado com um representante sul-americano de Polystachya e o pioneiro envolvendo biologia reprodutiva no gênero, embora Ackerman (1995) tenha sugerido que em P. concreta e $P$. foliosa (Hook.) Rchb. f., a produção de frutos ocorra através de autopolinização espontânea, na América Central. Além disso, esta a primeira menção de abelhas Meliponini atuando como polinizadores de espécies que oferecem pseudopólen como recurso em orquídeas.

O presente trabalho teve como objetivos estudar a biologia floral e reprodutiva de $P$. estrellensis e $P$. concreta, analisando aspectos da fenologia, morfologia floral, seus polinizadores e mecanismos de polinização, formas de reprodução, bem como o sucesso reprodutivo das espécies em condições naturais.

\section{Material e métodos}

A biologia reprodutiva e a polinização de Polystachya estrellensis Rchb. f. foram estudadas na Serra do Japi (aproximadamente $23^{\circ} 15^{\prime}$ S e $46^{\circ} 52^{\prime}$ W), no Município de Jundiaí, Estado de São Paulo, Brasil. A região é composta de matas mesofíticas semidecíduas, florestas mesofíticas semidecíduas de altitude e esparsos enclaves de lajeados rochosos (Leitão Filho 1992). A Serra do Japi é caracterizada por altitudes que variam entre $700 \mathrm{~m}$ e $1.300 \mathrm{~m}$ e temperaturas médias anuais entre $15,7^{\circ} \mathrm{C}$ e $19,2^{\circ} \mathrm{C}$. A região apresenta sazonalidade bem marcada, com períodos de estiagem no outono e no inverno e de chuvas mais intensas no verão. A precipitação média anual é de $1.500 \mathrm{~mm}$ a $1.907 \mathrm{~mm}$ (Pinto 1992). A população estudada é formada por cerca de 30 indivíduos distribuídos em uma área de mata mesofítica semidecídua.

A polinização e a biologia reprodutiva de Polystachya concreta (Jacq.) Garay \& H.R. Sweet foram estudadas na planície litorânea de Picinguaba (aproximadamente 2333' S e 4504' W), no Município de Ubatuba, Estado de São Paulo, Brasil. A área de estudo é composta predominantemente por florestas úmidas de planície ou floresta de restinga (Cesar \& 
Monteiro 1995). A região é caracterizada por altitudes que variam entre $0 \mathrm{~m}$ e $50 \mathrm{~m}$ e temperaturas médias anuais de aproximadamente $21^{\circ} \mathrm{C}$. A precipitação média anual é de cerca de 2.600 mm (Nimer 1977). A população estudada é composta por mais de 600 indivíduos distribuídos em uma área de mangue na planície litorânea.

Para acompanhamento da fenologia de Polystachya estrellensis e $P$. concreta foram realizadas visitas mensais às populações estudadas, entre janeiro de 1998 e março de 2000, para verificação do desenvolvimento de pseudobulbos, de inflorescências, aspectos sobre a antese e fenecimento das flores, e deiscência dos frutos. Para documentar o número de flores cleistógamas produzidas por Polystachya estrellensis em condições naturais foram realizadas visitas diárias em 12 plantas (12 inflorescências; 862 flores) na Serra do Japi, em janeiro de 2004.

O estudo da morfologia floral de Polystachya estrellensis (flores casmógamas e cleistógamas) e de $P$. concreta foi feito com auxílio de estereomicroscópio binocular, a partir de flores frescas coletadas no campo.

Os cortes anatômicos de Polystachya estrellensis foram feitos a partir de flores fixadas em FAA em etanol $50 \%$ por 48 horas e transferidas para álcool 70\%. Posteriormente, foi realizada a série de desidratação alcoólica, em álcool etílico, e alguns labelos foram emblocados em historresina, em moldes de polietileno. Para isso, foram realizadas as etapas de préinfiltração, infiltração e polimerização. Após a polimerização, os moldes foram levados à estufa e, posteriormente, os blocos foram fixados em suportes de madeira. Os cortes com 9-12 $\mu \mathrm{m}$ de espessura foram feitos em micrótomo de rotação, distendidos sobre as lâminas com água destilada e secos em estufa. Os cortes foram corados com azul de toluidina $1 \%$ (Sakai 1973) e, após serem secos, as lamínulas foram montadas com "Permount".

As observações dos visitantes florais, da freqüência de visita e dos mecanismos de polinização de Polystachya estrellensis foram realizadas na Serra do Japi, entre 17 e 19 de dezembro de 1998, 18 e 25 de janeiro de 1999, 21 e 23 de fevereiro de 1999, e 7 e 9 de janeiro de 2000, totalizando 170 horas de observação. As observações em Polystachya concreta foram feitas em Picinguaba, entre 14 e 16 de janeiro de 1999, 3 e 8 de fevereiro de 1999, e 25 e 26 de fevereiro de 2000, perfazendo 111 horas. Para ambas as espécies o período de observação aconteceu entre 7h30 e 17h30. Para detectar a possível ocorrência de polinizações noturnas, flores foram marcadas ao final de cada dia de observação e conferidas na manhã do dia seguinte.

Os tratamentos para verificação do sistema reprodutivo de Polystachya estrellensis e $P$. concreta foram realizados em casa de vegetação na Universidade Estadual de Campinas,

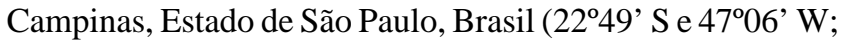
$700 \mathrm{~m}$ de altitude), a partir de plantas coletadas nas áreas de estudo. Para ambas as espécies foram usados 21 indivíduos, nos quais foram realizados quatro tipos de tratamentos: autopolinização manual, autopolinização espontânea, emasculação e polinização cruzada. Apenas uma inflorescência de cada planta foi usada nos tratamentos, que foram feitos a partir de flores do primeiro dia de antese. O número de flores usadas em cada tratamento variou, dependendo do total produzido em cada inflorescência.

As informações sobre o sucesso reprodutivo de Polystachya estrellensis em condições naturais foram obtidas na Serra do Japi, em novembro de 1999, sendo amostradas 12 inflorescências de diferentes indivíduos. Para P. concreta, essas informações foram obtidas em Picinguaba, em novembro de 1999, sendo amostradas 46 inflorescências. Para ambas as espécies, o número de flores amostrado variou, e dependeu do total produzido em cada inflorescência. Os dados de taxa de frutificação foram obtidos a partir de frutos deiscentes.

O material testemunho de Polystachya estrellensis (E. R. Pansarin 1131) e P. concreta (E. R. Pansarin 216) foram depositados no Herbário da Universidade Estadual de Campinas (UEC), e o material entomológico no Museu de História Natural da Universidade Estadual de Campinas (ZUEC).

\section{Resultados e Discussão}

Polystachya estrellensis Rchb. f. ocorre como epífita ou raramente como rupícola em matas mesofíticas semidecíduas da Serra do Japi, enquanto P. concreta (Jacq.) Garay \& H. R. Sweet é epífita na região de mangue da planície litorânea de Picinguaba, ocorrendo principalmente sobre galhos de Rhizophora mangle L. Em Picinguaba, P. concreta, assim como Brassavola tuberculata Hook., ocorre exclusivamente na região de mangue (Ribeiro 1992). Polystachya estrellensis e $P$. concreta florescem no verão. Polystachya estrellensis floresce entre os meses de dezembro e janeiro, enquanto o período de floração de $P$. concreta estende-se de janeiro a fevereiro. As flores de ambas as espécies apresentam antese diurna e cada flor dura cerca de dois ou três dias.

A morfologia vegetativa e floral é semelhante para ambas as espécies. A altura dos indivíduos varia entre 5 e $14 \mathrm{~cm}$, embora plantas de Polystachya estrellensis possam atingir até $20 \mathrm{~cm}$ de altura. As folhas de $P$. concreta são verde-amareladas, enquanto as de $P$. estrellensis são verde-escuras. No início da primavera, cada indivíduo produz um novo pseudobulbo, que logo emite uma inflorescência terminal. A inflorescência pode ser racemosa em plantas pequenas ou uma panícula em plantas mais desenvolvidas. Cada inflorescência pode conter até 150 flores não ressupinadas. As flores são esverdeadas em $P$. estrellensis e verde-amareladas em $P$. concreta. As 
sépalas (c. de $3 \mathrm{~mm} \times 2,5 \mathrm{~mm}$ ) são ovais com ápice agudo e adnatas à base da coluna formando um mento. As sépalas laterais são assimétricas e a apical é simétrica. As pétalas (c. de 2,7 mm × $1 \mathrm{~mm}$ ) são linearlanceoladas com ápice agudo a obtuso. As sépalas de $P$. concreta são mais angulosas e deflexas, e o ápice das pétalas é mais afilado que as de P. estrellensis. $\mathrm{O}$ labelo é trilobado e apresenta uma protuberância na base. Os lobos laterais do labelo são falcados, triangulares em $P$. estrellensis e sub-quadráticos em $P$. concreta. O lobo apical é arredondado ou truncado em $P$. estrellensis e geralmente reniforme em $P$. concreta. O labelo de ambas as espécies apresenta superfície pulverulenta devido à presença de pseudopólen. $\mathrm{O}$ pseudopólen de $P$. estrellensis e $P$. concreta, assim como tem sido demonstrado para outras espécies de orquídeas (van der Pijl \& Dodson 1966, Davies \& Winters 1998, Davies et al. 2000, 2002, Davies \& Turner 2004a, b), é constituído de células esféricas derivadas de fragmentação de tricomas moniliformes e pluricelulares (figuras 1-2). A formação de pseudopólen representa a condição mais derivada no gênero Polystachya, sendo atribuída principalmente à seção Polystachya (Davies et al. 2002). Em P. estrellensis e $P$. concreta as células de pseudopólen são nucleadas, com citoplasma denso e com grânulos que podem ser constituídos de amido. Alguns autores têm sugerido que o pseudopólen de espécies de Polystachya é constituído por células vazias e sem valor nutritivo, atraindo os polinizadores por engano (Vogel 1978, Ackerman 1986). Trabalhos mais recentes, no entanto, revelam que o pseudopólen de algumas espécies de orquídeas, incluindo Polystachya, contém proteína e amido (Davies \& Winters 1998, Davies et al. 2000, 2002, Davies \& Turner 2004b), sendo nutritivo para as abelhas, como proposto previamente por Beck (1914). Da mesma forma, embora Kjellsson \& Rassmussen (1987) tenham sugerido que Dendrobium unicum atrai seus polinizadores por engano, seu pseudopólen apresenta grãos de amido (Davies \& Turner 2004a).

Ambas as espécies estudadas apresentam coluna curta e o labelo está disposto mais ou menos perpendicularmente em relação a ela. A antera, com c. de 0,6 mm de comprimento, é circular e branca. O polinário de Polystachya estrellensis e P. concreta possui duas polínias globosas, amarelo-pálidas e bipartidas, embora algumas espécies asiáticas do gênero possam apresentar quatro polínias (Dressler 1993). Para maiores detalhes a respeito da morfologia floral e ilustrações de $P$. estrellensis e $P$. concreta veja Hoehne (1949) e Pansarin (2000).

Os polinizadores de Polystachya estrellensis e $P$. concreta são espécies de pequenas abelhas nativas, solitárias e sociais (tabela 1). Polystachya estrellensis também foi visitada por Salpingogaster sp. (Diptera: Syrphidae), mas apenas os himenópteros atuaram como

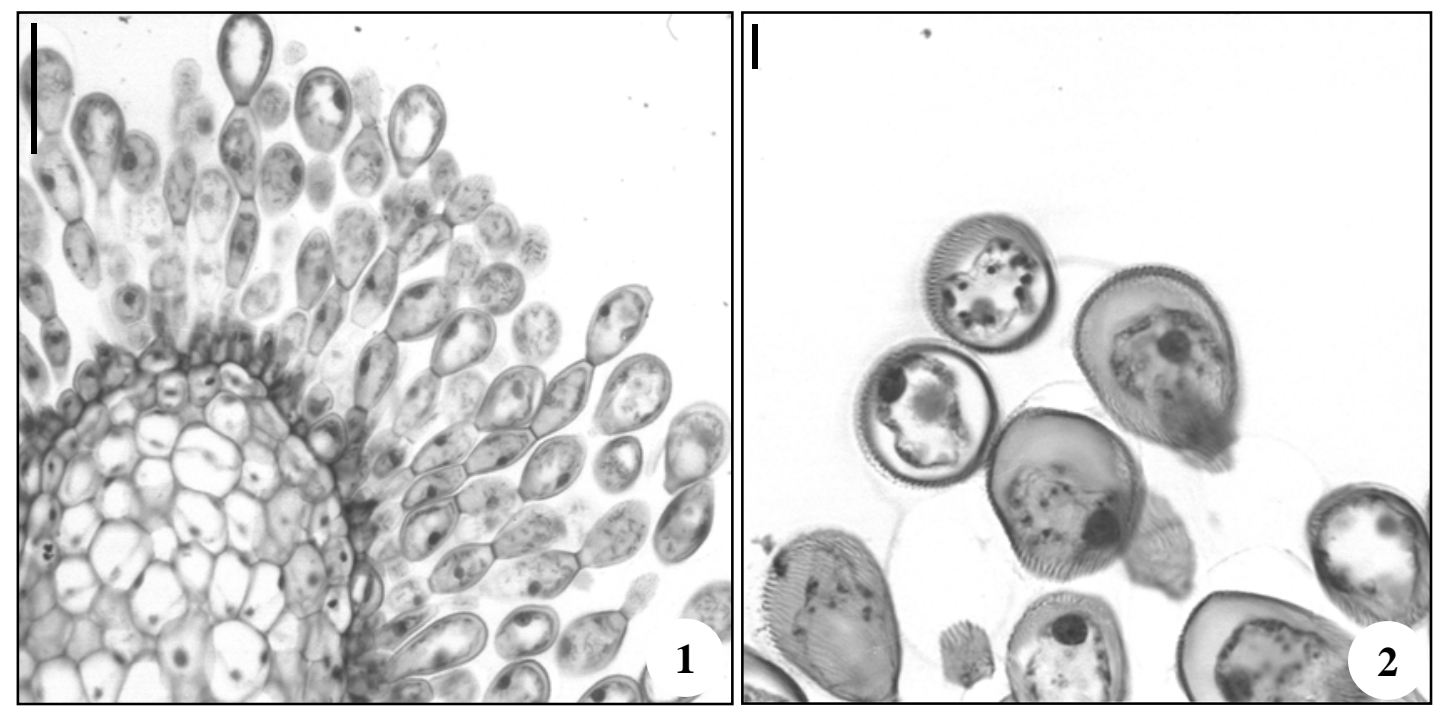

Figuras 1-2. Cortes transversais do labelo de Polystachya estrellensis Rchb. f. Note as células individualizadas derivadas da fragmentação dos tricomas moniliformes e pluricelulares. Barras $=100 \mu \mathrm{m}(1), 10 \mu \mathrm{m}(2)$.

Figures 1-2. Transversal sections of the lip of Polystachya estrellensis Rchb. f. Note the individualized cells derivate from moniliform and pluricelular trichomes fragmentation. Bars $=100 \mu \mathrm{m}(1), 10 \mu \mathrm{m}(2)$. 
Tabela 1. Polinizadores de Polystachya estrellensis Rchb. f. e P. concreta (Jacq.) Garay \& H. R. Sweet, na Serra do Japi e Picinguaba, respectivamente. A freqüência refere-se ao número total de visitas registradas nos períodos de floração de 1998 a 2000. (Valores entre parênteses $=$ freqüência relativa em porcentagem).

Table 1. Pollinators of Polystachya estrellensis Rchb. f. and P. concreta (Jacq.) Garay \& H. R. Sweet at Serra do Japi and Picinguaba, respectively. Frequency refers to the visitation numbers documented in the flowering period from 1998 to 2000. (Characters between parenthesis = relative frequency in percentage).

\begin{tabular}{|c|c|c|}
\hline \multirow[t]{2}{*}{ Espécies } & \multicolumn{2}{|c|}{ Freqüência } \\
\hline & P. estrellensis & P. concreta \\
\hline \multicolumn{3}{|l|}{ HALICTIDAE } \\
\hline Dialictus sp. & $16(10,6 \%)$ & $118(69 \%)$ \\
\hline \multicolumn{3}{|l|}{ APIDAE (MELIPONINI) } \\
\hline Melipona sp. & $6(4 \%)$ & - \\
\hline $\begin{array}{l}\text { Plebeia droryana } \\
\text { (Friese 1900) }\end{array}$ & $67(44,7 \%)$ & $21(12,3 \%)$ \\
\hline $\begin{array}{l}\text { Tetragonisca angustula } \\
\quad \text { (Latreille 1836) }\end{array}$ & $28(18,7 \%)$ & $2(1,2 \%)$ \\
\hline $\begin{array}{l}\text { Trigona spinipes } \\
\text { (Fabricius, 1793) }\end{array}$ & $33(22 \%)$ & $24(14 \%)$ \\
\hline \multicolumn{3}{|l|}{ APIDAE (TETRAPEDIINI) } \\
\hline Paratetrapedia aff. fervida & - & $6(3,5 \%)$ \\
\hline
\end{tabular}

polinizadores. A atividade das abelhas sociais (espécies de Plebeia, Trigona, Tetragonisca e Melipona) ocorreu durante todo o dia, desde 7 h30 até 17h30, enquanto as solitárias (espécies de Dialictus e Paratetrapedia) ocorreram principalmente no período da manhã. As visitas por Dialictus sp., assim como aconteceu com as demais espécies de abelhas, iniciaramse por volta das 7 h30. Neste horário, as visitas foram freqüentes, acontecendo em intervalos de aproximadamente 12 minutos. A partir das $9 \mathrm{~h} 30$ as visitas tornaram-se gradualmente mais escassas, cessando completamente entre $12 \mathrm{~h} 00$ e 13 h00. Plebeia droryana, Trigona spinipes (Fabricius, 1793) e Tetragonisca angustula foram os polinizadores mais freqüentes de $P$. estrellensis na Serra do Japi (tabela 1), sendo esta a primeira menção de abelhas Meliponini atuando como polinizadores de espécies que oferecem pseudopólen como recurso em orquídeas ( Roubik 2000). Já P. concreta foi polinizada predominantemente por Dialictus sp. em Picinguaba, que respondeu por 69\% das visitas (tabela 1). Algumas espécies de Polystachya, como P. flavescens (Lindl.) J. J. Sm. (Goss 1977) e P. rosea Ridl. (Pettersson \& Nilsson 1993), assim como observado em $P$. concreta, são polinizadas exclusivamente por Halictidae, um grupo de abelhas que também é muito importante como polinizador de vários grupos de orquídeas brasileiras (Singer \& Cocucci 1999).

Para Polystachya estrellensis e P. concreta o mecanismo de polinização foi semelhante ao descrito por Goss (1977) para P. flavescens. As abelhas pousaram sobre as sépalas laterais de uma das flores. Como as flores não são ressupinadas, as abelhas agarraram-se ao labelo e sépalas laterais com as pernas medianas e posteriores para ficarem com a porção ventral do tórax em contato com o pseudopólen (figuras 3-6), uma posição também chamada de supino. O pseudopólen foi coletado com as pernas dianteiras e medianas e depositado na face ventral do tórax das abelhas (figura 3) e, posteriormente, transferido para as escopas (Halictidae) ou corbículas (Meliponini) (figura 4). A coleta sempre se processou da extremidade para a base do labelo. Somente quando as abelhas coletaram pseudopólen na região da protuberância existente no labelo é que sua cabeça pode contatar o viscídio do polinário. A deposição do polinário ocorreu sempre na face frontal da cabeça das abelhas (figura 8). Goss (1977), no entanto, observou que a deposição de polinários de $P$. flavescens ocorre na porção dorsal do tórax de Dialictus aff. creberrimus. Nas espécies estudadas foram observados indivíduos de Trigona spinipes (figura 4) e Tetragonisca angustula (figuras 6-7) carregando até três ou quatro polinários cada um. Em ambas as localidades, as abelhas visitaram uma a poucas flores de cada inflorescência e cada uma das visitas durou cerca de 2 a 10 segundos.

Ambas as espécies de Polystachya exalam suave odor cítrico, que foi perceptível principalmente nos períodos em que os polinizadores foram mais freqüentes. Assim, não se pode descartar a hipótese de que a fragrância de $P$. estrellensis e $P$. concreta possa influenciar na atração dos polinizadores. Os principais constituintes da fragrância floral de $P$. estrellensis são monoterpenos, com sesquiterpenos presentes em menores concentrações (Reis et al. 2004). A presença de voláteis florais é geralmente considerada como efetiva em atrair abelhas sociais a curtas distâncias, promovendo maior especificidade dos visitantes florais, quando comparado com atração estritamente visual (Dobson 1994). Experimentos realizados com abelhas sociais, principalmente do gênero Apis, demonstraram que esses insetos podem discriminar fragrâncias quando associadas com alimento. Estudos de comportamento, aliados às análises químicas das fragrâncias florais, revelaram que apenas uma fração dos compostos é 

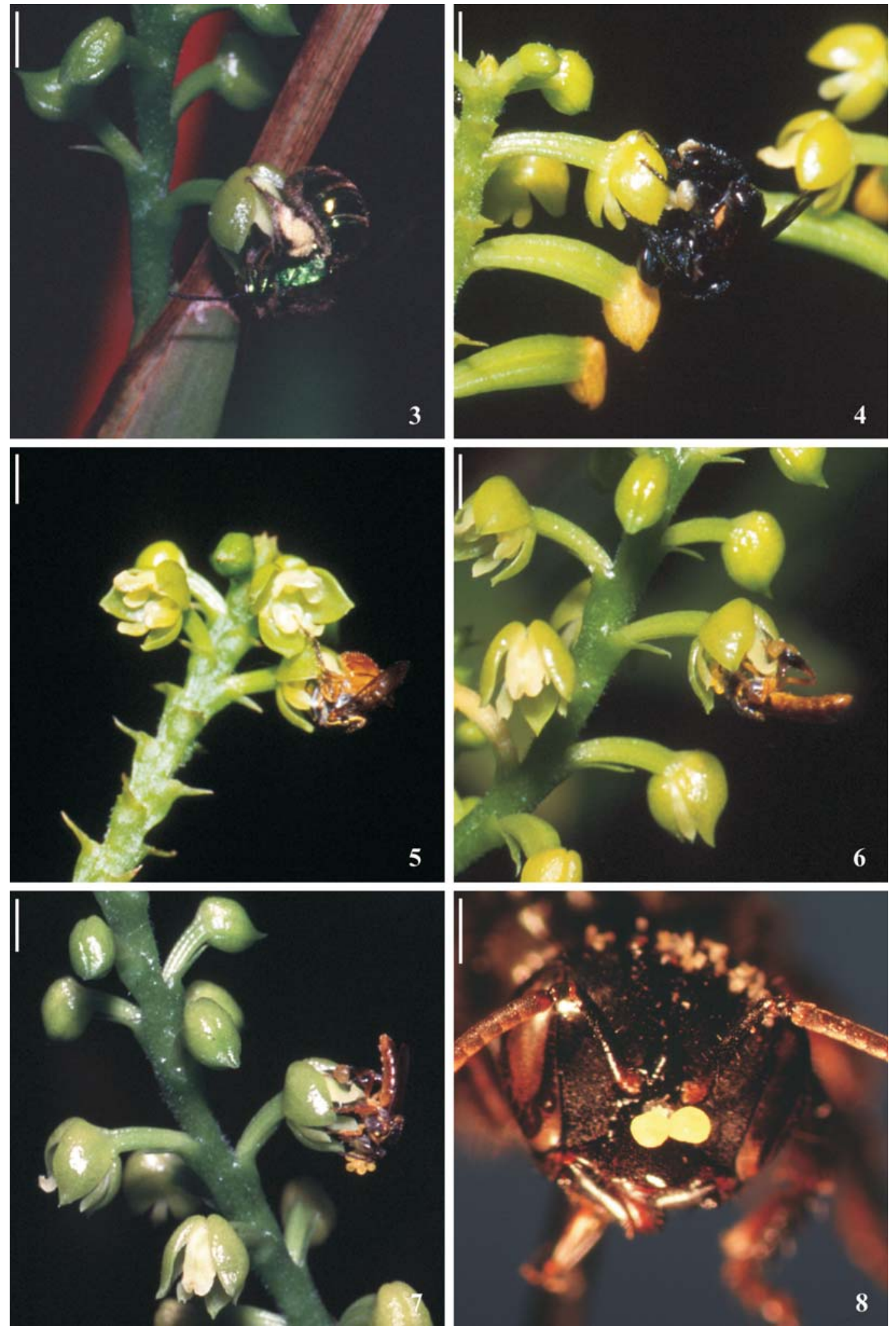

Figuras 3-8. Polystachya concreta (Jacq.) Garay \& H. R. Sweet, Polystachya estrellensis Rchb. f. e seus polinizadores. 3. Dialictus sp. recolhendo pseudopólen do labelo de Polystachya concreta. 4. Trigona spinipes (Fabricius, 1793) coletando pseudopólen de uma flor de P. estrellensis. Note as corbículas com pseudopólen. 5. Plebeia droryana (Friese 1900) recolhendo pseudopólen de P. estrellensis. 6. Tetragonisca angustula (Latreille 1836) coletando pseudopólen de P. concreta. 7. Tetragonisca angustula abandonando uma flor de $P$. concreta com três polinários na face frontal cabeça. 8. Detalhe da cabeça de Trigona spinipes com um polinário de $P$. estrellensis. Barras = 2 mm (3-7), 0,5 mm (8). 
perceptível para as abelhas, e que esses compostos são principalmente monoterpenos (Dobson 1994). Flores de Polystachya estrellensis apresentam concentrações consideráveis de geranial, entre outros monoterpenos, constituindo sua fragrância (Reis et al. 2004). Estudos mostraram que a fragrância existente no pólen de algumas angiospermas difere da fragrância de outras partes da mesma flor (Dobson et al. 1990, 1996), sendo perceptível para algumas espécies de abelhas (Dobson 1987, 1994). Knudsen \& Tollsten (1993) relataram que a fragrância do pólen de espécies do gênero Rosa (Rosaceae) é rica em compostos geranólicos. Dobson et al. (1987) demonstraram que geranial está presente no pólen de Rosa rugosa Thunb., que oferece pólen como recurso. Embora seja interessante o fato de substâncias que ocorrem no aroma do pólen de algumas espécies estarem presentes em uma espécie com pseudopólen como recurso, estudos ainda são necessários testando as substâncias no campo para comprovação de que o odor possa estar envolvido na atração dos polinizadores.

A maioria das flores de Polystachya estrellensis (96,8\%) é cleistógama, enquanto $P$. concreta produz apenas flores casmógamas (tabela 2). As flores de $P$. concreta, assim como as flores casmógamas de P. estrellensis (3,2\%), necessitam de um polinizador para a transferência de pólen. Ambas as espécies são autocompatíveis. Para P. concreta e para as flores casmógamas de $P$. estrellensis, frutos foram formados a partir das autopolinizações manuais e polinizações cruzadas (tabela 2). Não houve formação de frutos em flores emasculadas ou através das autopolinizações espontâneas. Tanto nas autopolinizações manuais como nas polinizações cruzadas realizadas, em flores casmóganas, a porcentagem de frutos formados foi de $59,1 \%$ e $68,7 \%$ para $P$. estrellensis, e $85,2 \%$ e $89,5 \%$ para $P$. concreta, respectivamente (tabela 2). Dos frutos formados por cleistogamia em P. estrellensis, 73,4\% tornaram-se deiscentes. Embora Lord (1981) tenha afirmado que espécies cleistógamas de Orchidaceae apresentam cleistogamia completa, $P$. estrellensis, assim como outros gêneros na família (van der Pijl \& Dodson 1966), podem produzir tanto flores casmógamas quanto cleistógamas. Além disso, flores cleistógamas de $P$. estrellensis apresentam número e tamanho dos elementos florais idênticos ao das flores casmógamas,

Tabela 2. Número de flores usadas e quantidade de frutos formados em cada tratamento para Polystachya estrellensis Rchb. f. e P. concreta (Jacq.) Garay \& H. R. Sweet, e sucesso reprodutivo de ambas as espécies em condições naturais. Números entre parênteses correspondem à porcentagem de frutos formados. As autopolinizações, polinizações cruzadas e emasculações referem-se às flores casmógamas. O sucesso reprodutivo em condições naturais refere-se às flores casmógamas e pseudocleistógamas.

Table 2. Flower number and fruit set in each treatment for Polystachya estrellensis Rchb. f. and P. concreta (Jacq.) Garay \& H. R. Sweet, and fruit set of both species at natural conditions. Numbers between parenthesis = percentage of fruit formation. The self- and cross-pollinations, and emasculations were based on chasmogamous flowers. The fruit set at natural conditions were based on chasmogamous and pseudocleistogamous flowers.

\begin{tabular}{|c|c|c|c|c|}
\hline \multirow{2}{*}{ Tratamentos } & \multicolumn{2}{|c|}{ P. estrellensis } & \multicolumn{2}{|c|}{ P. concreta } \\
\hline & Flores & Frutos & Flores & Frutos \\
\hline Autopolinização espontânea & 19 & - & 210 & - \\
\hline Autopolinização manual & 22 & $13(59,1 \%)$ & 210 & $179(85,2 \%)$ \\
\hline Emasculação & 6 & - & 210 & - \\
\hline Polinização cruzada & 16 & $11(68,7 \%)$ & 190 & $170(89,5 \%)$ \\
\hline Cleistogamia & 1.883 & $1.383(73,4 \%)$ & - & - \\
\hline Condições naturais & 965 & $844(87,5 \%)$ & 4.015 & $835(20,8 \%)$ \\
\hline
\end{tabular}

Figures 3-8. Polystachya concreta (Jacq.) Garay \& H. R. Sweet, Polystachya estrellensis Rchb. f. and pollinators. 3. Dialictus sp. collecting pseudopollen of the lip of Polystachya concreta. 4. Trigona spinipes (Fabricius, 1793) collecting pseudopollen from a flower of $P$. estrellensis. Note the corbiculae with pseudopollen. 5. Plebeia droryana (Friese 1900) collecting pseudopollen from $P$. estrellensis. 6. Tetragonisca angustula (Latreille 1836) collecting pseudopollen from P. concreta. 7. Tetragonisca angustula leaving a flower of $P$. concreta with three pollinaria on the frontal face of the head. 8. Detail of the head of Trigona spinipes with one pollinarium of $P$. estrellensis. Bars $=2 \mathrm{~mm}$ (3-7), $0.5 \mathrm{~mm}$ (8). 
características comuns às espécies pseudocleistógamas (Lord 1981). Polystachya estrellensis apresentou número semelhante de flores cleistógamas em plantas cultivadas em casa de vegetação $(96,7 \%)$ e em condições naturais $(94,8 \%)$. Portanto, a ocorrência de cleistogamia na espécie parece não estar associada com fatores ambientais (baixa precipitação e temperatura), como é comum para espécies pseudocleistógamas (Lord 1981). Uma base genética para determinar o grau de cleistogamia tem sido sugerida para várias espécies (Lord 1981). Outros estudos demonstraram que, embora fatores ambientais possam influenciar no grau de cleistogamia em plantas que produzem tanto flores casmógamas quanto cleistógamas, fatores genéticos parecem ser mais importantes (Clay 1982, 1983).

Os frutos formados por cleistogamia em Polystachya estrellensis, assim como aqueles derivados de polinizações manuais em ambas as espécies, apresentaram baixas taxas de aborto (tabela 2). O aborto dos frutos observado para $P$. estrellensis e $P$. concreta provavelmente está relacionado com a limitação de recursos, principalmente devido à alta taxa de frutificação a que foram submetidas às inflorescências nas polinizações experimentais, um processo semelhante ao que tem sido documentado para outros gêneros de orquídeas (Montalvo \& Ackerman 1987, Ackerman 1989, Zimmerman \& Aide 1989, Borba \& Semir 1998).

Autogamia tem sido considerada como uma forma de reprodução que promove baixa variabilidade genética (Faegri \& van der Pijl 1979), entretanto, espécies autógamas podem apresentar uma grande diversidade genética e, presumivelmente, grande adaptabilidade (Allard et al. 1968, Moeller \& Geber 2005). Em Polystachya estrellensis, as poucas flores casmógamas produzidas necessitam de um polinizador para transferência de pólen. Assim, a ocorrência de algumas flores casmógamas (geralmente uma a poucas por inflorescência) pode produzir frutos derivados de polinizações cruzadas, aumentando a variabilidade genética de $P$. estrellensis em relação às plantas estritamente autógamas. A autogamia tem sido interpretada como tendo evoluído a partir de espécies alógamas e tende a ser evitada devido à expressão de genes deletéricos recessivos (depressão por endogamia) (Lange \& Schemske 1985a, Catling 1990). Vários fatores, no entanto, podem favorecer a autogamia em plantas, como colonização de novas áreas por um a poucos indivíduos, ausência de polinizadores e seleção para adaptação local (Stebbins 1957, van der Pijl \& Dodson 1966, Lloyd 1979, Lange \& Schemske 1985b,
Catling 1990). Em matas mesofíticas semidecíduas da Serra do Japi, onde a taxa de frutificação de várias espécies de orquídeas é baixa, principalmente devido à escassez de polinizadores (Pansarin 2000), a estratégia apresentada por $P$. estrellensis em produzir tanto flores casmógamas quanto cleistógamas perece ser um importante fator que contribui positivamente para o sucesso reprodutivo da espécie, em relação a outras Epidendroideae não autógamas que ocorrem na região (Pansarin 2000, 2003). Além disso, a produção de flores cleistógamas pode assegurar que em condições climáticas adversas, principalmente em regiões que apresentam grande sazonalidade, como a Serra do Japi (Pinto 1992), frutos sejam formados, mesmo na escassez de polinizadores, um processo semelhante ao que tem sido demonstrado para outros grupos de plantas (e.g. Redbo-Torstensson \& Berg 1995, Lu 2002).

Agradecimentos - Os autores agradecem à Base Ecológica da Serra do Japi e ao Instituto Florestal pelas autorizações concedidas para realização dos trabalhos de campo; a G.J. Shepherd, M. Sazima, S. Buzato, V. Bittrich e aos assessores anônimos pelas sugestões; a J.H.A. Dutilh pela correção do abstract; a Fapesp (processo 98/05097-0) e ao CNPq pelo financiamento do projeto.

\section{Referências bibliográficas}

ACKERMAN, J.D. 1986. Mechanisms and evolution of fooddeceptive pollination systems in orchids. Lindleyana 1:108-113.

ACKERMAN, J.D. 1989. Limitations to sexual reproduction in Encyclia krugii (Orchidaceae). Systematic Botany 14:101-109.

ACKERMAN, J.D. 1995. An orchid flora of Puerto Rico and the Virgin Islands. New York Botanical Garden, New York.

ALLARD, R.W., JAIN, S.K. \& WORKMAN, P.L. 1968. The genetics of inbreeding species. Advances in Genetics 14:55-131.

BECK, G. 1914. Die Pollennachahmung in den Blüten der Orchideen-Gattung Eria. der Wissenschaften in Wien 123:1033-1046.

BORBA, E.L. \& SEMIR, J. 1998. Wind-assisted fly pollination in three Bulbophyllum (Orchidaceae) species occurring in the Brazilian campos rupestres. Lindleyana 13:203-218.

CATLING, P.M. 1990. Auto-pollination in the Orchidaceae. In Orchid Biology, reviews and perspectives (J. Arditti, ed.). Timber Press, Oregon, v.5, p.121-158.

CATLING, P.M. \& CATLING, V.R. 1991. A synopsis of breeding systems and pollination in North American orchids. Lindleyana 6:187-210.

CESAR, O. \& MONTEIRO, R. 1995. Florística e fitossociologia de restinga em Picinguaba (Parque Estadual da Serra do Mar), município de Ubatuba, SP. Naturalia 20:89-105. 
CLAY, K. 1982. Environmental and genetic determinants of cleistogamy in a natural population of the grass Danthonia spicata. Evolution 36:734-741.

CLAY, K. 1983. Variation in the degree of cleistogamy within and among species of the grass Danthonia. American Journal of Botany 70:835-843.

DAVIES, K.L. \& TURNER, M.P. 2004a. Pseudopollen in Dendrobium unicum Seidenf. (Orchidaceae): reward or deception? Annals of Botany 94:129-132.

DAVIES, K.L. \& TURNER, M.P. 2004b. Pseudopollen in Eria Lindl. Section Mycaranthes Rchb. f. (Orchidaceae). Annals of Botany 94:707-715.

DAVIES, K.L. \& WINTERS, C. 1998. Ultrastructure of the labelar epidermis in selected Maxillaria species (Orchidaceae). Botanical Journal of the Linnean Society 126:349-361.

DAVIES, K.L., WINTERS, C. \& TURNER, M.P. 2000. Pseudopollen: its structure and development in Maxillaria (Orchidaceae). Annals of Botany 85:887-895.

DAVIES, K.L., ROBERTS, D.L. \& TURNER, M.P. 2002. Pseudopollen and food-hair diversity in Polystachya Hook. (Orchidaceae). Annals of Botany 90:477-484.

DOBSON, H.E. 1987. Role of flower and pollen aromas in host-plant recognition by solitary bees. Oecologia 72:618-623.

DOBSON, H.E. 1994. Floral volatiles in insect biology. In Insect-Plant Interactions (E.A. Bernays, ed.). CRC Press, Boca Raton, v.5, p.47-81.

DOBSON, H.E., BERGSTRÖM, J., BERGSTRÖM, G \& GROTH, I. 1987. Pollen and flower volatiles in two Rosa species. Phytochemistry 26:3171-3173.

DOBSON, H.E., BERGSTRÖM, G. \& GROTH, I. 1990. Differences in fragrance chemistry between flower parts of Rosa rugosa Thunb. (Rosaceae). Israel Journal of Botany 39:143-156.

DOBSON, H.E., GROTH, I. \& BERGSTRÖM, G. 1996. Pollen advertisement: chemical contrasts between whole-flower and pollen odors. American Journal of Botany 83:877-885.

DRESSLER, R.L. 1981. The orchids: natural history and classification. Harvard University Press, Cambridge.

DRESSLER, R.L. 1993. Phylogeny and classification of the orchid family. Cambridge University Press, Cambridge.

FAEGRI, K. \& VAN DER PIJL, L. 1979. The principles of pollination ecology. $3^{\text {rd }}$ ed., Pergamon Press, New York.

GOSS, G.J. 1977. The reproductive biology of the epiphytic orchids of Florida 6. Polystachya flavescens (Lindley) J.J. Smith. American Orchid Society Bulletin 46:990-994.

HOEHNE, F.C. 1949. Iconografia de orquidáceas do Brasil. Instituto de Botânica, São Paulo.

KJELLSSON, G. \& RASMUSSEN, F.N. 1987. Does the pollination of Dendrobium unicum Seidenf. involve “pseudopollen”? Die Orchidee 38:183-187.

KNUDSEN, J.T. \& TOLLSTEN, L. 1993. Trends in floral scent chemistry in pollination syndromes: floral scent composition in moth-pollinated taxa. Botanical Journal of the Linnean Society 113:263-284.
LANGE, R. \& SCHEMSKE, D.W. 1985a. The evolution of self-fertilization and inbreeding depression in plants. I. Genetic Models. Evolution 39:24-40.

LANGE, R. \& SCHEMSKE, D.W. 1985b. The evolution of self-fertilization and inbreeding depression in plants. II. Empirical observations. Evolution 39:41-52.

LEITÃO FILHO, H.F. 1992. A flora arbórea da Serra do Japi. In História natural da Serra do Japi (L.P.C. Morellato, ed.). Editora da Unicamp/Fapesp, Campinas/São Paulo, p.40-62.

LLOYD, D.G. 1979. Some reproductive factors affecting the selection of self-fertilization in plants. American Naturalist 113:67-97.

LLOYD, D.G. \& SCHOEN, D.J. 1992. Self- and crossfertilization in plants. I. Functional dimensions. International Journal of Plant Science 153:358-369.

LORD, E.M. 1981. Cleistogamy: a tool for the study of floral morphogenesis, function and evolution. The Botanical Review 47:421-449.

LU, Y. 2002. Why is cleistogamy a selected reproductive strategy in Impatiens capensis (Balsaminaceae). Biological Journal of the Linnean Society 75:543-553.

MOELLER, D.A. \& GEBER, M.A. 2005. Ecological context of the evolution of self-pollination in Clarkia xantiana: population size, plant communities, and reproductive assurance. Evolution 59:786-799.

MONTALVO, A.M. \& ACKERMAN, J.D. 1987. Limitations to fruit production in Ionopsis utricularioides (Orchidaceae). Biotropica 19:24-31.

MORRISON, A. 1997. Polystachya. In The illustrated encyclopedia of orchids (A. Pridgeon, ed.). Timber Press, Oregon, p.237-238.

NIMER, E. 1977. Climatologia da região sudeste do Brasil. Revista Brasileira de Geografia 34:3-48.

PABST, G. 1950. Notas sôbre "Polystachya estrellensis, Rchb. f.”. Orquidea 12:167-169.

PANSARIN, E.R. 2000. Biologia reprodutiva e morfologia floral de espécies de Orchidaceae em diferentes ambientes no Estado de São Paulo. Dissertação de mestrado, Universidade Estadual de Campinas, Campinas.

PANSARIN, E.R. 2003. Biologia reprodutiva e polinização em Epidendrum paniculatum Ruiz \& Pavón (Orchidaceae). Revista Brasileira de Botânica 26:203-211.

PETTERSSON, B. \& NILSSON, L.A. 1993. Floral variation and deceit pollination in Polystachya rosea (Orchidaceae) on an inselberg in Madagascar. Opera Botanica 121:237-245.

PINTO, H.S. 1992. O clima da Serra do Japi. In História natural da Serra do Japi (L.P.C. Morellato, ed.). Editora da Unicamp/Fapesp, Campinas/São Paulo, p.30-38.

REDBO-TORSTENSSON, P. \& BERG, H. 1995. Seasonal cleistogamy: a conditional strategy to provide reproductive assurance. Acta Botanica Neerlandica 44:247-256. 
REIS, M.G., PANSARIN, E.R., SILVA, U.F., AMARAL, M.C.E. \& MARSAIOLI, A.J. 2004. Pollinator attraction devices (floral fragrances) of some Brazilian orchids. Arkivoc 4:89-97.

RIBEIRO, J.E. 1992. Florística e padrões de distribuição da família Orchidaceae na planície litorânea do núcleo de desenvolvimento Picinguaba, município de Ubatuba, Parque Estadual da Serra do Mar, SP. Dissertação de mestrado, Universidade Estadual Paulista, Rio Claro.

ROUBIK, D.W. 2000. Deceptive orchids with Meliponini as polinators. Plant Systematics and Evolution 222:271-279.

SAKAI, W.S. 1973. Simple method for differential staining of paraffin embedded plant material using toluidine blue O. Stain Technology 43:247-249.

SIMPSON, B.B. \& NEFF, J.L. 1981. Floral rewards: alternatives to pollen and nectar. Annals of the Missouri Botanical Garden 68:301-322.
SINGER, R.B. \& COCUCCI,A.A. 1999. Pollination mechanism in southern Brazilian orchids which are exclusively or mainly pollinated by halictid bees. Plant Systematics and Evolution 217:101-117.

SINGER, R.B. \& KOEHLER, S. 2004. Pollinarium morphology and floral rewards in Brazilian Maxillariinae (Orchidaceae). Annals of Botany 93:39-51.

STEBBINS, G.L. 1957. Self-fertilization and population variability in higher plants. American Naturalist 91:337-354.

VAN DER PIJL, L. \& DODSON, C.H. 1966. Orchid flowers, their pollination and evolution. University of Miami Press, Coral Gables.

VOGEL, S. 1978. Evolutionary shifts from reward to deception in pollen flowers. In The pollination of flowers by insects (A.J. Richards, ed.). Academic Press, London, p.89-96.

ZIMMERMAN, J.K. \& AIDE, M. 1989. Patterns of fruit production in a neotropical orchid: pollinator $v$ s. resource limitation. American Journal of Botany 76:67-73. 